\title{
How Impurities Responsible for Recalls Emerge in Hand Sanitizers
}

\author{
Farsheed Shahbazi-Raz ${ }^{1 *}$, Neda Mashhadi', Bukola R. Aremu1, Paul Tucci', Justin Binder², \\ John F. Trant ${ }^{1 *}$ \\ ${ }^{1}$ Department of Chemistry and Biochemistry, University of Windsor, 401 Sunset Ave., Windsor, ON Canada; \\ ${ }^{2}$ Peak Processing Solutions, Tecumseh, ON, Canada.
}

\section{farsheed@uwindsor.ca; j.trant@uwindsor.ca}

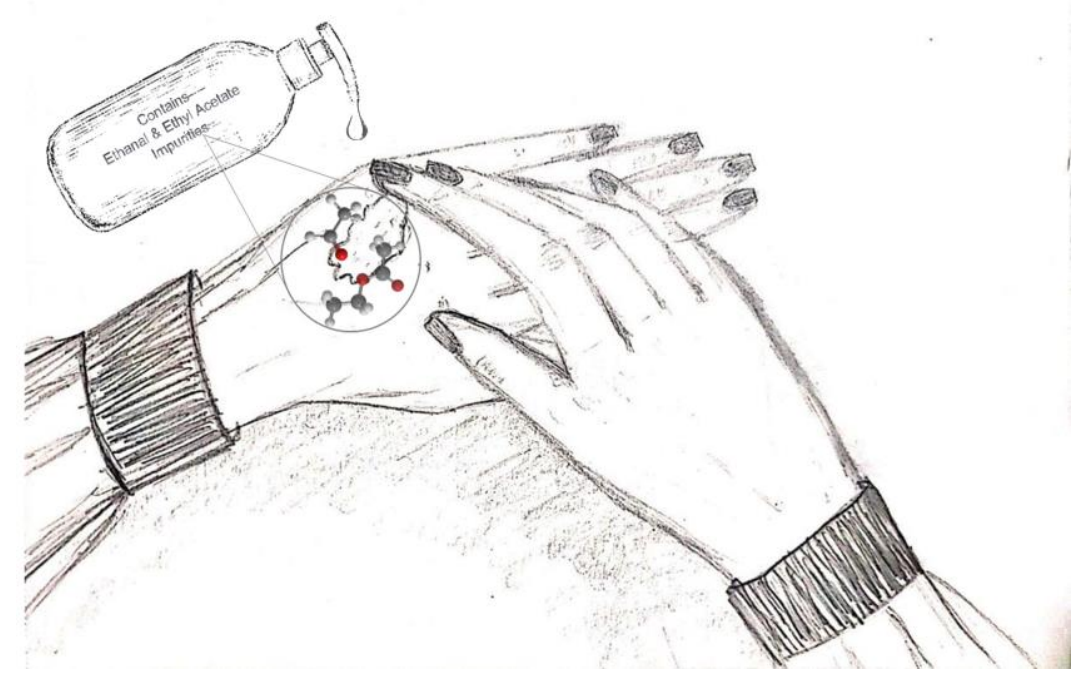

\section{Abstract:}

The global pandemic has created an unprecedented demand for alcohol-based hand sanitizers. This stimulated the entry of many new producers of hand sanitizers, both to provide a new business during the general shutdowns, and to meet the needs of society. Similarly, this created a need for alcohol sources well beyond what had been produced for the consumer market. This has led to numerous recalls of formulations in both the United States and Canada for exceeding the limits of several key impurities, arising from oxidized forms of alcohols, that could risk consumers' health. Some of these recalls likely arise from the use of substandard ingredients, but others are less easily explained. However, the inclusion of hydrogen peroxide, and the possibly introduction of metal salts from processing could explain the levels of oxidative impurities. This study investigates these questions experimentally using the standard WHO formula as the base formulation, and finds that these impurities do readily arise in the presence of metal salts.

Keywords: hand sanitizer, hydrogen peroxide, oxidation chemistry, commercial recalls, acetaldehyde, ethanal, ethyl acetate. 


\section{Introduction}

The sudden emergence of SARS-CoV-2, its quick spread, and the continual emergence of novel variants of concern showing some avoidance of immunosurveillance, has put the global health, economy, and response to other existential challenges such as climate change, in danger. ${ }^{1}$ As of early January 2022, COVID-19 has been implicated in about 5.46 million deaths and 300 million confirmed positive cases worldwide. ${ }^{2}$ In the early days of the pandemic, before the airborne nature of the virus was confirmed, fomite transmission was a major concern and there was (and in some cases remains) a focus on sanitizing surfaces and hands. ${ }^{3}$ Regardless of its utility for this disease, sanitizers will likely continue to be more and more present in public spaces in society moving forward as alcohol-based hand Sanitizers (ABHS) and handwashing effectively reduce the spread of pathogens. ${ }^{4}$ For healthcare settings, the CDC recommends ABHS with 60-95 percent alcohol (isopropanol or ethanol); too little alcohol and the sanitizer is not effective, too much and it also loses miscibility and effectiveness. In most clinical contexts, an ABHS is favoured over soap and water unless hands are visibly soiled (wherein alcohol based sanitizers are not effective) due to evidence of higher compliance for ABHS use than for soap and water. ${ }^{5}$ Many of the hand sanitizers on the market are derived from the WHO recommended liquid formulation. The WHO specifically recommends $80 \%$ ethanol or $75 \%$ isopropyl alcohol. ${ }^{6}$ These ABHS are effective against gram-positive and gram-negative bacteria, as well as enveloped and non-enveloped viruses, mycobacteria, and fungi; $85 \%$ ethanol eliminates $10^{5}$ (99.999\%) gram negative or gram positive bacteria in 15 seconds. ${ }^{7}$ Ethanol is highly efficient against viruses, while isopropanol is thought to be the better bactericidal agent, but both are more than suitable. Alcohols mixed together may have a synergistic impact. ${ }^{8}$

Along with the alcohol and water, ABHS typically contain a range of thickening agents, humectants, stabilizers, fragrances, emollients, moisturisers, emulsifiers, and plant-sourced essential oils. Humectants, such as Glycerol, are widely employed to prevent skin dehydration, extending the time it takes for alcohol to evaporate and boosts its biocidal activity. ${ }^{9}$ Emollients and moisturizers, like aloe vera, help to replenish part of the water lost from the skin. Hydrogen peroxide $\left(\mathrm{H}_{2} \mathrm{O}_{2}\right)$ is recommended by the $\mathrm{WHO}$ as an antiseptic to eliminate bacterial spores that might be introduced during manufacture. ${ }^{6,10}$

Raw materials destined for the pharmaceutical and food industries must typically meet minimum quality criteria, such as those defined in monographs published by the Food Chemicals Codex (FCC) and the United States Pharmacopeia (USP). During the COVID-19 epidemic, there was an unprecedented increase in demand for hand sanitizer products, resulting in global shortages of USP grade, pharmaceutical, and food-grade ethanol, and isopropyl alcohol (IPA). ${ }^{11}$ 
The FDA and Health Canada both issued a notice to industry on April 15, 2020 on the time-limited approval of particular sources of fuel or technical-grade ethanol for use in the production of hand sanitizers. ${ }^{12}$ Allowable impurities under these temporary regulations listed in Table 1. In addition, if the total of all other impurities exceeds 300 ppm, all individual impurities must be determined and pass the interim limits listed in Table 2. Despite this relaxation in standards, some new ABHS have been recalled by both the American FDA and Health Canada as they have been determined to contain unacceptable grades of ethanol or cancerous chemicals such as ethanal (acetaldehyde), ethyl acetate, methanol or the unauthorized medicinal ingredient $n$-propanol. ${ }^{13}$ In many cases, this likely arises from poor quality feedstocks as methanol and propanol impurities are commonly found in lower grades of ethanol; however, this is not always the cause as many producers obtain their ethanol from certified sources with excellent quality control. Consequently, ethanal and ethyl acetate appear to be arising spontaneously in the product. How is this happening, and how can it be suppressed?

Table 1. FDA and Health Canada limits on Class 1 impurities in ABHS.

\begin{tabular}{|l|l|l|}
\hline Impurity & \multicolumn{1}{l}{$\begin{array}{l}\text { Interim Limit under } \\
\text { FDA policy }\end{array}$} & $\begin{array}{l}\text { Interim Limit under } \\
\text { Health Canada policy }\end{array}$ \\
\hline Methanol & NMT 630 ppm & NMT 200 ppm \\
\hline Benzene & NMT 2 ppm & NMT 2 ppm \\
\hline Ethanal (Acetaldehyde) & NMT 50 ppm & NMT 75 ppm \\
\hline Acetal (1,1-diethoxyethane) & NMT 50 ppm & Not reported \\
\hline Sum of all other impurities & NMT 300 ppm & NMT 300 ppm \\
\hline
\end{tabular}

Table 2. FDA limits on Class 2 impurities in ABHS should all non-Class 1 impurities combined exceed 300 ppm.

\begin{tabular}{|l|l|} 
Impurity & $\begin{array}{l}\text { Interim Limit under FDA and } \\
\text { Health Canada policy }\end{array}$ \\
\hline Acetone & NMT 4400 ppm \\
\hline n-propanol (1-propanol) & NMT 1000 ppm \\
\hline Ethyl acetate & NMT 2200 ppm \\
\hline Sec-butanol (2-butanol) & NMT $6200 \mathrm{ppm}$ \\
\hline Iso-butanol (2-Methyl-1-propanol) & NMT 21700 ppm \\
\hline n-butanol (1-butanol) & NMT $1000 \mathrm{ppm}$ \\
\hline iso-amyl alcohol (3-Methyl-1-butanol) & NMT 4100 ppm \\
\hline Amyl alcohol & NMT 4100 ppm \\
\hline
\end{tabular}

Of all the potential impurities, ethanal is of specific concern. It may cause cancer in consumers and could led to serious illness or death. ${ }^{14}$ Ethanal is suspected to be genotoxic, and potentially carcinogenic, when in direct contact with tissue. ${ }^{12}$ Ethyl acetate, acetal, and acetic acid, 
the other three impurities of interest are important as they would be downstream byproducts arising from ethanal formation [Note to the preprint reader: We are better quantifying these impurities and the latter two are not included yet in the analysis below, their omission does not affect the headline conclusions of the work]. In this study, we have investigated possible pathways which may lead to the formation of these impurities in ABHS by studying synthetic formulations generated with common additives, and quantifying the content of the impurities of interest as a function of time.

\section{Materials and methods}

\subsection{Materials}

USP Ethanol, 200 proof, was purchased from IGPC Ethanol Inc. (Leamington, Canada). Glycerol was purchased from Windy Point Soap Making Supplies Inc. (Calgary, Canada), carbomer (Carbopol 945) was obtained from the Lubrizol Corporation (Wickliffe, OH, USA). Hydrogen Peroxide 35\%, ferrous sulphate, Triethanolamine 98\%, and EDTA were purchased from SigmaAldrich (St. Louis, USA).

\subsection{Methods}

\subsubsection{Preparation of the hand sanitizer}

The ABHS (Table 3) were prepared by adding each ingredient in the order listed at ambient temperature $\left(23.5^{\circ} \mathrm{C}\right)$, one by one, with thorough mixing to homogeneity after each addition. The only exception to this process is Formula 6 , in which the carbomer was added to the water, $\mathrm{pH}$ neutralized with Triethanolamine (to $\mathrm{pH}$ 7.0), before the other ingredients were added. Once all ingredients were added, the solutions were mixed for an additional 30 minutes at 300 RPM. Each formulation was divided and stored in two separate sealed vessels (limited headspace above the sample, but sealed under atmospheric conditions), one at room temperature, and the second at $45^{\circ} \mathrm{C}$ for up to 60 days. Over this time period, $1 \mathrm{ml}$ aliquots were withdrawn for analysis by GCMS.

\subsubsection{GC-MS analysis method}

ABHS analysis was carried out using a PerkinElmer Clarus 590 GC with a SQ 8 MS (EI) detector. GCMS was equipped with an automatic liquid sampler with a $5 \mu \mathrm{L}$ volume capacity syringe. An Elite-624sil MS L 30m (ID 0.25mm, $1.4 \mu \mathrm{m}$ film) with flow rates of $1.0 \mathrm{~mL} \mathrm{~min}^{-1}$ of Helium was used for separation of target hand sanitizer contaminants. MS scan mode in range of 50-300 amu was used for analysis while the transfer line and source were kept at 150 and $250^{\circ} \mathrm{C}$, respectively. Initial oven temperature was set to $35^{\circ} \mathrm{C}$ and held for $2 \mathrm{~min}$. The temperature was ramped first 
to $75^{\circ} \mathrm{C}$ at $10^{\circ} \mathrm{C} \cdot \mathrm{min}^{-1}$ and held for $1 \mathrm{~min}$; then to $180^{\circ} \mathrm{C}$ at $20^{\circ} \mathrm{C} \cdot \mathrm{min}^{-1}$ and held for $1 \mathrm{~min}$ and finally, ramped to $260{ }^{\circ} \mathrm{C}$ at $20^{\circ} \mathrm{C} \mathrm{min}^{-1}$ and hold for $2 \mathrm{~min}$. Helium was used as the carrier gas, with a flow rate of $6 \mathrm{~mL} \cdot \mathrm{min}^{-1}$. The inlet was set to split flow of $120: 1$ and $1 \mu \mathrm{L}$ of sample was injected.

\section{Results and discussion}

We considered that ABHS impurities can arise from three sources: 1) impure raw materials; 2) process-related impurities where potential contaminants can be introduced during manufacture, such as gasoline and benzene, where transfer occurs from machinery or containers; ${ }^{12 b}$ or emergent formulation-based impurities that arise from chemical reactions of pure ingredients that can be affected by the environment or the presence of unexpected catalysts. The chemical community is aware of how easy it is for even very low and undesirable catalyst loading can affect chemistry. ${ }^{15}$

\section{Evaluation of formulations:}

Table 3. Composition of the evaluated ABHS.

\begin{tabular}{|c|c|c|c|c|c|c|c|c|c|}
\hline INGREDIENTS & $F=0$ & $F-1$ & F-2 & $F-3$ & $F-4$ & F-51 & F-52 & $F-6$ & F-7 \\
\hline Distilled Water & --- & $\begin{array}{r}\text { To } \\
100 \%\end{array}$ & $\begin{array}{r}\text { To } \\
100 \%\end{array}$ & -- & -- & $\begin{array}{r}\text { To } \\
100 \%\end{array}$ & $\begin{array}{r}\text { To } \\
100 \%\end{array}$ & $\begin{array}{r}\text { To } \\
100 \%\end{array}$ & $\begin{array}{r}\text { To } \\
100 \%\end{array}$ \\
\hline HPLC Water & --. & --- & --. & $\begin{array}{r}\text { To } \\
100 \%\end{array}$ & $\begin{array}{r}\text { To } \\
100 \%\end{array}$ & --. & - & --- & - \\
\hline $\begin{array}{l}\text { Hydrogen peroxide } \\
(35 \%)\end{array}$ & --- & --- & $0.36 \%$ & --- & $0.36 \%$ & $0.36 \%$ & $0.36 \%$ & $0.36 \%$ & $0.36 \%$ \\
\hline Glycerol & --- & $1.45 \%$ & $1.45 \%$ & $1.45 \%$ & $1.45 \%$ & $1.45 \%$ & $1.45 \%$ & $1.45 \%$ & $1.45 \%$ \\
\hline Ferrous Sulfate & --- & --- & --- & --- & --- & $0.10 \%$ & $0.02 \%$ & --- & --- \\
\hline Carbopol 945 & --- & --- & --- & --- & --- & --- & -- & --- & $0.5 \%$ \\
\hline EDTA & --- & --- & --- & --- & --- & --- & - & $0.10 \%$ & -- \\
\hline Ethanol & $100 \%$ & $80 \%$ & $80 \%$ & $80 \%$ & $80 \%$ & $80 \%$ & $80 \%$ & $80 \%$ & $80 \%$ \\
\hline
\end{tabular}

Nine different formulations were produced to investigate the emergence of above impurities from highly pure feedstocks (Table 3). F-0 was created with $100 \%$ ethanol as a control and to determine if measurable impurities arise due to simple storage. F-1 contains $80 \%$ ethanol, and the WHOrecommended dose of glycerol-it was completed with distilled water. F-2 is identical to F-1 with the addition of the $\mathrm{H}_{2} \mathrm{O}_{2}$. The F-3 and F-4 formulations are identical to F-1 and F-2, respectively, with the distilled water replaced by HPLC water to evaluate the effect of water sources. F-5 and F-5-1 are prepared by adding $0.1 \%$ and $0.02 \% \mathrm{Fe}_{2} \mathrm{SO}_{4}$ to $\mathbf{F}-2$ respectively. Metal impurities could 
catalyze the oxidation of ethanol by $\mathrm{H}_{2} \mathrm{O}_{2}$ and/or oxygen. ${ }^{16}$ Iron salts would not be expected in ABHS but may be present due to the manufacturing environment (e.g., equipment, containers or even ingredients). Formulation F-6 was obtained by adding $0.1 \%$ EDTA as a chelating agent to F-2; EDTA would sequester any metals present in the solution and acts as a control on the rest of the formulation. The final formulation, a gel rather than a liquid, F-7, was obtained by adding $0.5 \%$ of carbomer to F-2. The physical and chemical properties of all liquid formulas are similar, all clear colourless liquids, except F-7 which is a gel-liquid formulation with a viscosity of 12,400 cps at $25^{\circ} \mathrm{C}$, imitating common gel-like formulations that are commercially available.

\section{Formulation Stability Tests}

To determine that all formulations were valid, and stable, a centrifugation assay was carried out. The samples were centrifuged at $3000 \mathrm{rpm}$ for 30 minutes at room temperature, no pellet or separation was observed. The temperature stability of each sample was evaluated by storing aliquots of the materials in duplicate under four different conditions: $5^{\circ} \mathrm{C}, 23.5^{\circ} \mathrm{C}, 45^{\circ} \mathrm{C}$ and $55^{\circ} \mathrm{C}$ for three months; in all cases the materials retained their consistency. On another set of aliquots of the above samples a freeze-thaw cycle was performed, heating and cooling the samples between -10 and $+42^{\circ} \mathrm{C}$, with two cycles every $24 \mathrm{~h}$, for 2 weeks (28 cycles total). Daily visual checks were performed. ${ }^{17}$ All formulations were stable under all these tests.

\section{Data analysis (GC-MS):}

We tracked the emergence of ethanal in our formulations and believed it would be time dependent. This was only partially the case. In our pure ethanol, F-0, the concentration began and remained below $54 \mathrm{ppm}$ at maximum, even at $45^{\circ} \mathrm{C}$, with the average remaining well under 50 ppm (Figure 1). By adding glycerol and distilled water in F-1, there is no meaningful change in the concentration of ethanal; however, at $45^{\circ} \mathrm{C}$, ethanal steadily rises to 298 ppm after 45 days. In F-2, wherein we added the $\mathrm{H}_{2} \mathrm{O}_{2}$, even at room temperature ethanal concentration spikes immediately before falling off (there is no ethanal detectable in the source $\mathrm{H}_{2} \mathrm{O}_{2}$ ); in samples stored at $45^{\circ} \mathrm{C}$, this increase is far more significant rising to $300 \mathrm{ppm}$. In F-3 and F-4 wherein we replaced the distilled water in F-1 and F-2 with HPLC water respectively (Fig.1b), the pattern resembles F-1 and F-2. Glycerol alone induces a rise in ethanal, and $\mathrm{H}_{2} \mathrm{O}_{2}$ a larger rise, and this is accentuated at higher temperatures.

We were surprised that simply including WHO-recommended levels of highly purified ingredients (not necessarily the feedstock in commercial sanitizers) was sufficient to raise ethanal levels above FDA and Health Canada levels. But we believed that this was not the full story for 
the recalls: even small amounts of metal salts could potentially catalyze decomposition, the generation of reactive oxygen species, and ethanal formation. ${ }^{18}$ This could easily be introduced from any rust in water lines or processing machinery. Consequently, we added both 1000 and $200 \mathrm{mg} / \mathrm{L} \mathrm{FeSO}_{4}$ to F-2 to generate F-5(1) and F-5(2) (Fig. 1c). The ethanal concentration in the presence of $1000 \mathrm{mg} / \mathrm{L}$ of ferrous sulfate rose right away in the first few days, and this happens at both test temperatures. In F-5(2), the lower the concentration of metal salt, the initial rise is lower, but the maximum ethanal concentration reached is higher (726 ppm, 15-fold the FDA limit); curiously we do not see a significant effect of temperature on either reaction. Ethanal levels are higher than that observed in any other formulation suggesting that catalysis is occurring. For F-6 we added the metal chelator EDTA to F-2 to sequester any metal impurities (Fig. 1d). EDTA does appear to stabilize the solution, especially at $45^{\circ} \mathrm{C}$. Finally, we investigated the effect of adding an "inert" gelling agent (carbomer) on F-7 (Fig. 1e). Carbomer is an acrylic acid polymer, and we neutralized it with ethanolamine to generate the mixed salt in solution as is generally done in the cosmetic industry. This also increases the concentration of ethanal compared to the native $\mathbf{F - 2 .}$ 



Figure 1. Analysis of ethanal concentration in ABHS. Analysis in room temperature was shown by solid lines and in $45^{\circ} \mathrm{C}$ was shown by dashed lines. a Comparison of the ethanol blank, and the samples with glycerol, and glycerol and hydrogen peroxide added; b Comparison with samples using HPLC-grade instead of distilled water; c Comparison between samples spiked with ferrous sulfate and the metal free formula; d Comparison between EDTA spiked and distilled water prepared standard formulations. E Comparison between standard formulations and the carbomer gel formulation.

Adding additives initiates ethanol oxidation to ethanal. Although it is well established that this can arise from yeast or bacterial metabolism, ${ }^{19}$ this is unlikely in a formally antiseptic formulation. Other data from our lab demonstrates that these formulations are highly effective for eliminating bacterial and yeast cultures (see supporting information, Table S1). Instead, the data 
is consistent with the mechanism being partially due to the presence of metal salts that can generate ROS to oxidize ethanol. This is not unprecedented.

Ethanal is generated as the primary selective product in the gas phase reaction of ethanol vapour over copper, vanadium, and molybdenum metal oxide catalysts via oxidative dehydrogenation. ${ }^{20}$ Similarly, in solution phase, adding ethanol to a mixture of vanadyl ions and $\mathrm{H}_{2} \mathrm{O}_{2}$ results in a minor yield of ethanal which increases as a function of ethanol concentration. ${ }^{21}$ Ethanol oxidation by aqueous $\mathrm{H}_{2} \mathrm{O}_{2}$ and ferric salts has also been reported. ${ }^{16}$ Merz and Waters' proposed a reasonable free radical chain reaction mechanism to explain the oxidation, with hydroxyl radicals produced by the interaction between the iron centre and hydrogen peroxide initiating oxidation process. ${ }^{16 \mathrm{~b}}$ The primary products of such a ferric ion-catalyzed oxidation, according to Heitler and collaborators, were ethanal and acetal. ${ }^{16 a}$ It seems feasible that a small concentration of $\mathrm{H}_{2} \mathrm{O}_{2}$ in the presence of metal impurities such as $\mathrm{Na}, \mathrm{Mg}, \mathrm{Ca}$, or Fe could be the reason for the observed generation of ethanal in $\mathrm{ABHS}$.

However, it is curious that ethanal concentrations do not always rise steadily in our ABHS formulations: initial high levels can fall off, and the rise also seems to slow at various threshold values. There also appears to be an induction period for some of the examples. We considered whether this was because ethanal was not the final product of the process, but simply an intermediate. In the presence of ethanol and acidic catalysts, ethanal can be readily be converted to 1,1-Diethoxyethane, confusingly referred to as "acetal" (Scheme 1). ${ }^{22}$ Health Canada requests acetal content be provided in the USP alcohol monograph but has no explicit limit, while the FDA mandates less than 50 ppm in ABHS; under normal circumstances this is well above the extant amount present due to ethanal content and the presence of water; ${ }^{12 a}$ acetal formation is more favoured in anhydrous conditions. ${ }^{22 a, b}$ It is not likely the reason that ethanal levels are stabilizing. Further oxidation to acetic acid and esterification to ethyl acetate may be one potential end point for this process. To determine the possibility of this process to occur, we quantified ethyl acetate levels as a function of time (Figure 2), especially as it is another regulated impurity (note, the acetic acid intermediate is not regulated, as at low concentrations vinegar is generally regarded as safe).

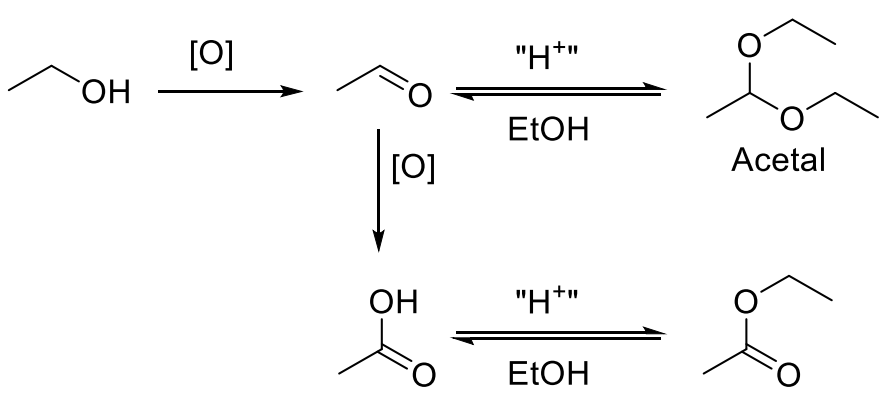


Scheme 1. Proposed oxidation and sequestration pathways. Acetal is contraindicated in $\mathrm{ABHS}$ due to the relatively high concentration of water and lack of strong acid catalyst.

16, 20-21 The concentration of ethyl acetate at room temperature and at $45^{\circ} \mathrm{C}$ is lower than 100 ppm in the ethanol feedstock (F-0, Fig 2a). Even by preparing glycerol and $\mathrm{H}_{2} \mathrm{O}_{2}$ containing F-1 and F-2 (Fig. 2b), and F-3 and F-4 (Fig. 2c) the maximum concentration ethyl acetate remains below 100ppm. Adding the iron salts, F-5(1) and F-5(2), and letting stand at ambient temperature, does slightly increase the concentration of ethyl acetate reaching a maximum of 149 ppm after 45 days. However, by increasing temperature to $45^{\circ} \mathrm{C}$ the rate of oxidation increases and the and the concentration of ethyl acetate increases daily, reaching 632 ppm, approximately 9 times higher than the formula without heavy metal impurities and around 4 times higher than the ambient temperature. Adding EDTA (F-6) keeps the ethyl acetate levels low, and although the carbomer gelling agent raises the initial levels, this might be due to the presence of residual acetic acid in the polymer being consumed rather than any independent catalytic activity (Fig. 2d). 
a


b
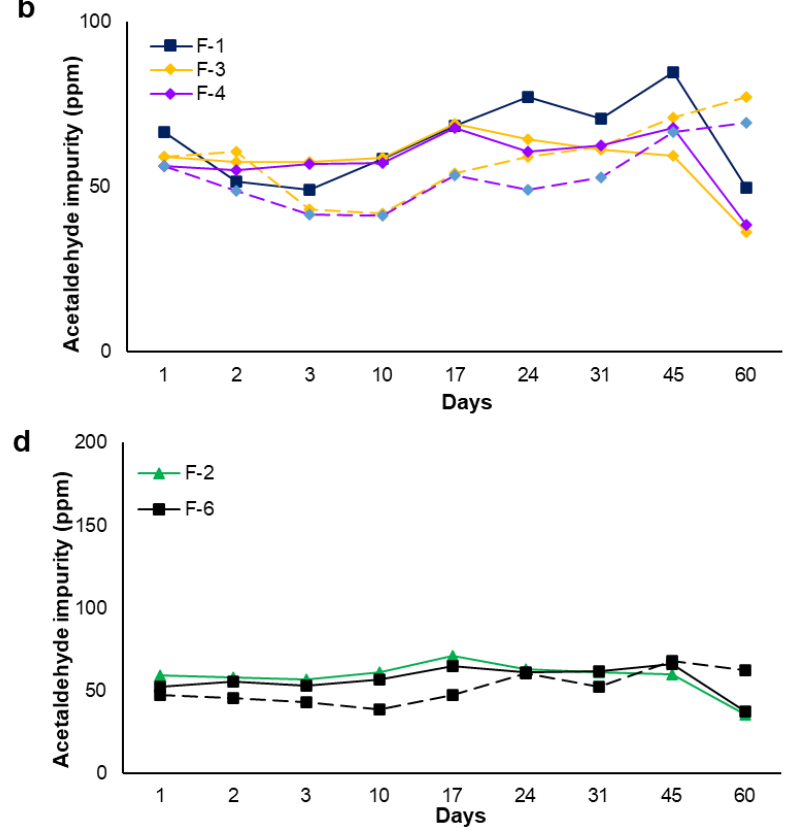

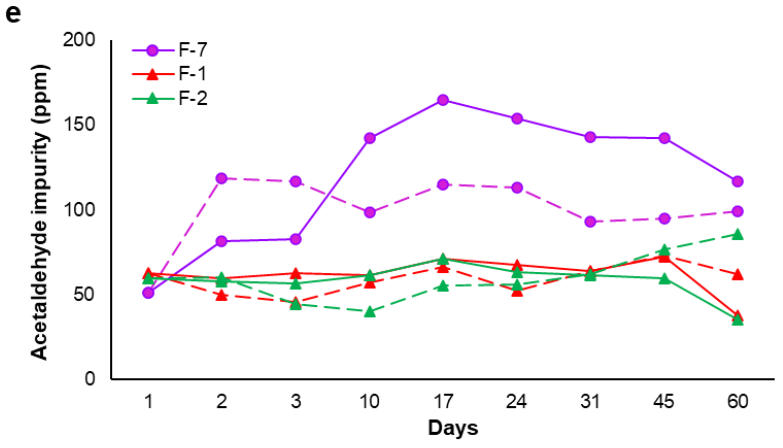

Figure 2. Analysis of ethyl acetate concentration in ABHS. Analysis in room temperature was shown by solid lines and in $45^{\circ} \mathrm{C}$ was shown by dashed lines.

Consequently, the only factor that increases ethyl acetate content is the presence of metal salts. This is potentially partially due to the increased ethanal content, but they might also be acting as Lewis Acids to accelerate the traditional Fischer esterification process. This is, after all, one of the industrial synthesis of ethanol and acetic acid is used to make ethyl acetate in industry. ${ }^{23}$ It is also potentially possible that ethyl acetate is arising directly from the disproportionation and dehydrogenation of ethanol; a process used to make ethyl acetate directly with copper catalysts (Equation 1).24 
We consider this latter process extremely unlikely as it does require a steel autoclave under high pressure temperature. ${ }^{25}$ Ethanol can be selectively oxidized to ethyl acetate in the presence of ethanal and phosphoric acid, ${ }^{26}$ but the strong acid is lacking in ABHS. It is far likelier that we are seeing a simple acceleration of the background Fisher process.

\section{Conclusion}

Impurities in ABHS have been responsible for multiple recalls of commercial sanitizers as the levels of the impurities present have been deemed to put citizens' health at risk. Although some of these impurities likely arose due to impure feedstocks, we propose that some are arising from the presence of metallic impurities that are introduced in manufacturing or processing. These can interact with the hydrogen peroxide to generate reactive oxygen species that can then oxidize ethanol. These results should help producers consider their manufacturing lines and may help identify and prevent such issues in the future.

1. Li, Q.; Guan, X.; Wu, P.; Wang, X.; Zhou, L.; Tong, Y.; Ren, R.; Leung, K. S. M.; Lau, E. H. Y.; Wong, J. Y.; Xing, X.; Xiang, N.; Wu, Y.; Li, C.; Chen, Q.; Li, D.; Liu, T.; Zhao, J.; Liu, M.; Tu, W.; Chen, C.; Jin, L.; Yang, R.; Wang, Q.; Zhou, S.; Wang, R.; Liu, H.; Luo, Y.; Liu, Y.; Shao, G.; Li, H.; Tao, Z.; Yang, Y.; Deng, Z.; Liu, B.; Ma, Z.; Zhang, Y.; Shi, G.; Lam, T. T. Y.; Wu, J. T.; Gao, G. F.; Cowling, B. J.; Yang, B.; Leung, G. M.; Feng, Z., Early transmission dynamics in Wuhan, China, of novel coronavirus-infected pneumonia. $N$. Engl. J. Med. 2020, 382 (13), 1199-1207.

2. Dong, E.; Du, H.; Gardner, L., An interactive web-based dashboard to track COVID-19 in real time. The Lancet Infectious Diseases 2020, 20 (5), 533-534.

3. Kampf, G.; Kramer, A., Epidemiologic background of hand hygiene and evaluation of the most important agents for scrubs and rubs. Clin. Microbiol. Rev. 2004, 17 (4), 863-93.

4. Kratzel, A.; Todt, D.; V'Kovski, P.; Steiner, S.; Gultom, M.; Thao, T. T. N.; Ebert, N.; Holwerda, M.; Steinmann, J.; Niemeyer, D.; Dijkman, R.; Kampf, G.; Drosten, C.; Steinmann, E.; Thiel, V.; Pfaender, S., Inactivation of severe acute respiratory syndrome coronavirus 2 by WHO-recommended hand rub formulations and alcohols. Emerg. Infect. Dis. 2020, 26 (7), 1592-1595.

5. Healthcare Infection Control Practices Advisory Committee CDC Core Practices for Infection Prevention in All Healthcare Settings Centres for Disease Control (USA): Atlanta, GA, 2017.

6. World Health Organization Guide to local production: WHO-recommended handrub formulations; World Health Organization,: Geneva, Switzerland, 2010.

7. Cure, L.; Van Enk, R.; Tiong, E., A systematic approach for the location of hand sanitizer dispensers in hospitals. Health Care Manag. Sci. 2014, 17 (3), 245-58.

8. Deshpande, A.; Fox, J.; Wong, K. K.; Cadnum, J. L.; Sankar, T.; Jencson, A.; Schramm, S.; Fraser, T. G.; Donskey, C. J.; Gordon, S., Comparative antimicrobial efficacy of two hand sanitizers in intensive care units common areas: A randomized, controlled trial. Infect. Control Hosp. Epidemiol. 2018, 39 (3), 267271.

9. Roeslan, M. O.; Richi, M.; Drestia, A. M.; Widyarman, A. S., Efficacy of World Health Organization-recommended homemade hand sanitizer against bacteria and fungus. J. Indones. Dent. Ass. 2021, 4 (2). 
10. Medina-Cordoba, L. K.; Valencia-Mosquera, L. L.; Tarazona-Diaz, G. P.; Arias-Palacios, J. D. C., Evaluation of the efficacy of a hydrogen peroxide disinfectant. Int. J. Phar. Pharmaceut. Sci. 2018, 10 (10), 104-108.

11. This includes suppliers in Windsor-Essex with whom the authors worked to source and formulate ABHS is March 2020. The authors receive no financial benefits for these sanitizers and are not involved in their sale or continued production.

12. (a) Technical-grade ethanol for the manufacture of hand sanitizers and hard-surface disinfectants during the COVID-19 pandemic: Risk assessment summary report.

http://www.canada.ca/en/health-canada/services/drugs-health-products/natural-nonprescription/legislation-guidelines/covid19-technical-grade-ethanol-hand-sanitizer/risk-assessmentsummary-report.html (accessed January 4, 2021); (b) Temporary Policy for Preparation of Certain Alcohol-Based Hand Sanitizer Products During the Public Health Emergency (COVID-19) Guidance for Industry. https://www.fda.gov/media/136289/download (accessed January 4, 2021).

13. (a) FDA updates on hand sanitizers consumers should not use; U.S. Food and Drug Administration: Washington, DC, 2021; (b) Health Canada warns about certain hand sanitizers that may pose health risks (Part 2 - March 31, 2021 to present); Health Canada: Ottawa, Canada, Jan 4, 2021, 2021.

14. Salaspuro, M., Acetaldehyde and gastric cancer. J. Digest. Dis. 2011, 12 (2), 51-59.

15. Avanthay, M.; Bedford, R. B.; Begg, C. S.; Böse, D.; Clayden, J.; Davis, S. A.; Eloi, J.-C.; Goryunov, G. P.; Hartung, I. V.; Heeley, J.; Khaikin, K. A.; Kitching, M. O.; Krieger, J.; Kulyabin, P. S.; Lennox, A. J. J.; Nolla-Saltiel, R.; Pridmore, N. E.; Rowsell, B. J. S.; Sparkes, H. A.; Uborsky, D. V.; Voskoboynikov, A. Z.; Walsh, M. P.; Wilkinson, H. J., Identifying palladium culprits in amine catalysis. Nature Catalysis 2021, 4 (12), 994-998.

16. (a) Heitler, C.; Scaife, D. B.; Thompson, B. W., The oxidation of ethanol by hydrogen peroxide. Part I. Catalysis by ferric ion. Journal of the Chemical Society A: Inorganic, Physical, Theoretical 1967, (0), 1409-1413; (b) Kremer, M. L., Oxidation of Ethyl Alcohol by a Mixture of Hydrogen Peroxide and Ferric Salts. Nature 1959, 184 (4687), 720-720.

17. Anchisi, C.; Maccioni, A. M.; Sinico, C.; Valenti, D., Stability studies of new cosmetic formulations with vegetable extracts as functional agents. II Farmaco 2001, 56 (5), 427-431.

18. Forbes, F. S.; Van Splinter, P. A., Liquid Rocket Propellants. In Encyclopedia of Physical Science and Technology (Third Edition), Meyers, R. A., Ed. Academic Press: New York, 2003; pp 741-777.

19. Liu, S.-Q.; Pilone, G. J., An overview of formation and roles of acetaldehyde in winemaking with emphasis on microbiological implications. Int. J. Food Sci. Technol. 2000, 35 (1), 49-61.

20. Takei, T.; Iguchi, N.; Haruta, M., Synthesis of acetoaldehyde, acetic acid, and others by the dehydrogenation and oxidation of ethanol. Catal. Surveys Asia 2011, 15 (2), 80-88.

21. Ravishankar, H. N.; Rao, A. V. S.; Ramasarma, T., Ethanol-dependent oxygen consumption and acetaldehyde formation during vanadyl oxidation by H2O2. Molecular and Cellular Biochemistry 1996, 154 (2), 101-106.

22. (a) Rudrawar, S. B., R. C.; Chakraborti, A. K. , Perchloric acid adsorbed on silica gel $\left(\mathrm{HClO}_{4}-\mathrm{SiO}_{2}\right)$ as an extremely efficient and reusable catalyst for 1,3-dithiolane/dithiane formation. Synthesis 2006, (16), 2767-2771; (b) Green, T. W.; P. G. M. Wuts, Reactivity Chart: Protection for the carbonyl group. In Protective Groups in Organic Synthesis, 3rd ed.; Wiley-Interscience, New York, : Ney York, NY, 1999; pp 724-727; (c) Capeletti, M. a. R.; Balzano, L.; de la Puente, G.; Laborde, M.; Sedran, U., Synthesis of acetal (1,1-diethoxyethane) from ethanol and acetaldehyde over acidic catalysts. Appl. Catal. A: General 2000, 198 (1), L1-L4; (d) Meadows, G. W.; Darwent, B. D., The reactions of acetaldehyde with methanol. Can. J. Chem. 1952, 30 (7), 501-506.

23. È. A. Blyumberg, G. E. Z., Z. K. Maizus, N. M. Emanuel', "Differences in the oxidation mechanism of liquid and gaseous ethyl alcohol". Dokl. Akad. Nauk SSSR 1960, 133, 144 
24. Santacesaria, E.; Carotenuto, G.; Tesser, R.; Di Serio, M., Ethanol dehydrogenation to ethyl acetate by using copper and copper chromite catalysts. Chemical Engineering Journal 2012, 179, 209220.

25. G.E. Zaikov and Z.K. Maizus, M. I. V. a. N. M. E., Neftekhimiya, 1967, 7

260.

26. Denisov, E. T., Chapter 3 The Oxidation of Alcohols, Ketones, Ethers, Esters and Acids in Solution. In Comprehensive Chemical Kinetics, Bamford, C. H.; Tipper, C. F. H., Eds. Elsevier: 1980; Vol. 16, pp 125203. 